\title{
Psychometric properties of the adult resilience indicator
}

\begin{tabular}{|c|c|}
\hline \multicolumn{2}{|c|}{$\begin{array}{l}\text { Authors: } \\
\text { Martina Kotzé1 } \\
\text { Petrus Nel}\end{array}$} \\
\hline \multicolumn{2}{|c|}{$\begin{array}{l}\text { Affiliations: } \\
{ }^{1} \text { UFS Business School, } \\
\text { University of the Free State, } \\
\text { Bloemfontein, South Africa }\end{array}$} \\
\hline \multicolumn{2}{|c|}{$\begin{array}{l}{ }^{2} \text { Department of Industrial } \\
\text { Psychology, University of the } \\
\text { Free State, Bloemfontein, } \\
\text { South Africa }\end{array}$} \\
\hline \multicolumn{2}{|c|}{$\begin{array}{l}\text { Correspondence to: } \\
\text { Martina Kotzé }\end{array}$} \\
\hline \multicolumn{2}{|c|}{$\begin{array}{l}\text { Email: } \\
\text { kotzem@ufs.ac.za }\end{array}$} \\
\hline \multicolumn{2}{|c|}{$\begin{array}{l}\text { Postal address: } \\
\text { PO Box 339, Bloemfontein } \\
9338 \text {, South Africa }\end{array}$} \\
\hline \multicolumn{2}{|c|}{$\begin{array}{l}\text { Dates: } \\
\text { Received: } 24 \text { Apr. } 2013 \\
\text { Accepted: } 17 \text { July } 2013 \\
\text { Published: } 27 \text { Sept. } 2013\end{array}$} \\
\hline \multicolumn{2}{|c|}{$\begin{array}{l}\text { How to cite this article: } \\
\text { Kotzé, M., \& Nel, P. (2013). } \\
\text { Psychometric properties of } \\
\text { the adult resilience indicator. } \\
\text { SA Journal of Industrial } \\
\text { Psychology/SA Tydskrif vir } \\
\text { Bedryfsielkunde, 39(2), Art. } \\
\text { \#1132, } 11 \text { pages. http:// } \\
\text { dx.doi.org/10.4102/sajip. } \\
\text { v39i2.1132 }\end{array}$} \\
\hline \multicolumn{2}{|c|}{$\begin{array}{l}\text { Copyright: } \\
\text { (C) 2013. The Authors. } \\
\text { Licensee: AOSIS } \\
\text { OpenJournals. This wor } \\
\text { is licensed under the } \\
\text { Creative Commons } \\
\text { Attribution License. }\end{array}$} \\
\hline \multicolumn{2}{|l|}{ Read online: } \\
\hline 口ifing & $\begin{array}{l}\text { Scan this QR } \\
\text { code with your } \\
\text { smart phone or } \\
\text { mobile device } \\
\text { to read online. }\end{array}$ \\
\hline
\end{tabular}

Orientation: Researchers need to assess the psychometric rigour of resilience measuring scales.

Research purpose: The purpose of the study was to assess the psychometric properties of the South African Adult Resilience Indicator (ARI).

Motivation for the study: Researchers have not previously published the psychometric properties of the South African Adult Resilience Indicator.

Research design, approach and method: The authors used a cross-sectional quantitative research design. A sample of 789 young adults participated in the study. Cross-validation allowed the authors to confirm (using the validation sample) the validity of the ARI structure they obtained during initial testing (using the calibration sample). They investigated two measurement models (the original factor structure and a one-dimensional factor structure).

Main findings: The original factor structure presented the data and the proposed theory better than did the one-dimensional factor structure. The authors found acceptable goodness of fit for the ARI. More specifically, they found invariance (in terms of equal factor loadings, covariances and error variances) in the calibration and validation samples. They also found acceptable reliability estimates for each of the eight sub-scales.

Practical/managerial implications: The results can help researchers and practitioners interested in measuring resilience in adults to choose a resilience measure and to select an appropriate measure for their populations and contexts.

Contribution/value-add: Previous research has clearly shown that reliable and valid resilience measures are necessary. It is also necessary to assess the psychometric properties of the currently available instruments and to publish the findings. This study has helped by examining the psychometric properties of the South African Adult Resilience Indicator.

\section{Introduction}

\section{Background to the study}

Research into resilience has increased substantially over the past two decades. This interest is because of a move away from 'deficit' models of illness and psychopathology because resilience theory focuses on understanding healthy development despite risk and on strengths rather than on weaknesses (Windle, Bennett \& Noyes, 2011). Therefore, resilience theory uses research that Masten and colleagues initiated (Masten, 2001) and researchers generally view it as a positive reaction or adaptation in the face of risk or adversity.

Most of the research on psychological resilience originates from the world of developmental psychology. Up to now, it has focused primarily on the resilience of at-risk children, problem adolescents and dysfunctional families (Luthans, Youssef \& Avolio, 2007; Visser, 2007). However, positive psychologists now recognise that resilience involves everyday skills and psychological strengths that one can identify, measure, maintain and nurture in people of all ages and psychological conditions (Masten \& Reed, 2002).

This positive view of resilience has also been taken to the workplace (Avolio \& Luthans, 2006; Luthans, 2002; Luthans, Avolio, Avey \& Norman, 2007). Luthans defined resilience in the workplace as the 'positive psychological capacity to rebound, to "bounce back" from adversity, uncertainty, conflict, failure, or even positive change, progress and increased responsibility' (Luthans 2002, p. 58).

Together with hope, optimism and self-efficacy, researchers regard resilience as an important element of psychological capital - a person's positive psychological state of development (Luthans et al., 2007). Various researchers have emphasised the importance of resilience in the 
workplace because of its role in handling organisational crises (French \& Holden, 2012). It counteracts the negative effects of innovation project failures (Moenkemeyer, Hoegl \& Weiss, 2012) and fosters desirable outcomes in terms of the individual-organisational relationship (Ollier-Malateree, 2010), to name a few. Because average performance can no longer meet today's rapidly growing expectations, organisations need people who can thrive on chaos, learn proactively and grow through hardships and excel no matter how many or how intense the inevitable setbacks are (Luthans et al., 2007). Initial research has found a positive relationship between resilience and workplace performance outcomes, job satisfaction, organisational commitment as well as work wellness (Carvalho, Carvo, Martin, Campos, \& Castillo, 2006; Kotzé \& Lamb, 2012; Luthans, Avolio et al., 2007; Norman, Avey, Nimnicht \& Pigeon, 2010; Youssef, 2004; Youssef \& Luthans, 2007).

Several researchers and scholars have generated theories and developed frameworks related to resilience, whilst empirical evidence has led to the development of models and instruments that operationalise the concept (Ahern, Kielh, Sole \& Byers, 2006). Nevertheless, the complexities of defining the concept of resilience are widely recognised, especially in the behavioural sciences (Windle et al., 2011). Some researchers regard resilience as a fixed trait (like hardiness) that might assist in a resilient response from the individual level (Bartone, 1989) or a personal quality that reflects the ability to cope with stress (Connor \& Davidson, 2003). However, others define resilience by including internal and external protective factors (such as family support) that might facilitate a resilient outcome (Visser, 2007; Windle, 2011). This creates several challenges when developing an operational definition of resilience (Ungar et al., 2008; Windle, 2011).

Furthermore, measuring resilience is also problematic. International researchers have made several attempts to measure resilience in adolescents and adults (Block \& Kremen, 1996; Connor \& Davidson, 2003; Friborg, Hjemdal, Rosenvinge, \& Martinussen, 2003; Johnson, Gooding, Wood \& Tarrier, 2010; Salahuddin \& O’Brien, 2011; Sinclair \& Wallston, 2004; Villabos-Galvis, Arevalo-Ojeda, RojasRivera, 2012; Wagnild \& Young, 1993). However, these scales are not widely adopted and no one scale is preferred to the others. Different approaches to measuring resilience across studies have led to inconsistencies relating to the nature of potential vulnerabilities and protective processes.

This diversity in measuring resilience has raised questions about the extent to which researchers into resilience are measuring resilience or something entirely different (Windle et al., 2011). In addition, the psychometric properties of many of these instruments are either not available or questionable (Ahern et al., 2006; Windle et al., 2011). Windle et al. (2011) reviewed nineteen resilience measures - four of which were refinements of the original measure - with regard to their psychometric properties and found that all the measures had some missing information in their psychometric properties.
Most (nine) of the measures focused on assessing resilience at the level of individual characteristics or resources only and only two of these measures presented a good theoretical basis to justify the item selection. According to Windle et al. (2011), the conceptual and theoretical adequacy of a number of the scales was questionable and they found no 'gold standard' amongst 15 measures of resilience. Overall, three measures, including the Resilience Scale for Adults (Friborg et al., 2003), the Connor-Davidson Resilience Scale (Connor \& Davidson, 2003) and the Brief Resilience Scale (Smith et al., 2008) received the highest ratings, although Windle et al. (2011) concluded that one can regard the quality of these questionnaires as only moderate.

Ungar et al. (2008) caution that the perspectives of those outside of western and Eurocentric cultures have had little influence on the discourse about resilience. Most psychometric validation studies only collect data from Western cultures. They preclude an evaluation of their universal application. Attempts to adapt resilience measures to non-Western societies have proved difficult (Friborg, Hjemdal \& Stiles, 2010). In addition, there is currently no single measure of resilience available for studies that span the life of a person (Windle et al., 2011). Consequently, researchers and clinicians have little robust evidence to inform their choice of a resilience measure and may make arbitrary and inappropriate selections for their populations and contexts.

Research to fathom the determinants, associations and promotion of resilience in the workplace requires reliable and valid measures of resilience to ensure data quality. In the South African context, the Adult Resilience Indicator (ARI) (Visser, 2007; 2009) is currently the only locally developed resilience questionnaire that measures resilience in adults. However, researchers have not evaluated the psychometric properties of the ARI and its application in different situations and age groups (young adults, the middle aged and the elderly) and/or published the evaluations to date.

Windle et al. (2011) and Ahern et al. (2006) reason that researchers need to undertake further work to assess current questionnaires and to publish studies on the psychometric development and evaluation of resilience instruments and scales. In 2005, the International Epidemiological Association European Questionnaire Group found that the attention researchers give to questionnaire development and validation is often inadequate and, even when wellconstructed questionnaires exist, other researchers do not always use them and miss opportunities to improve them.

\section{Aim of the study}

In the light of these arguments, the aim of this study was to assess the stability of the factor structure of the ARI (Visser, 2007; 2009). The authors also investigated the reliability estimates associated with each of the eight sub-scales. 


\section{Contribution to the field}

This study will help to fill the gap that recent research has identified with regard to the need for assessing the psychometric properties of the resilience instruments that are currently available.

The authors give a brief overview of the resilience construct, as well as a description of the ARI, below. A discussion of the research design, results, conclusion and recommendations follow.

\section{Resilience: Making meaning of the construct}

Researchers have proposed various definitions of resilience (Hjemdal, Friborg, Stiles, Martinussen \& Rosenvinge, 2006, p. 84). However, they generally describe resilience as an ability of people to:

1. Cope successfully and adapt to situational discontinuities and risk environments (Griffith, 2007; Johnson \& Howard, 2002; Luthans, Avey, Clapp-Smith \& Li, 2008; Mandleco \& Peery, 2000; Miller, 2003; Ong \& Bergeman, 2004).

2. Overcome or 'bounce back' from disadvantaged circumstances, risk and adversity (Arehart-Treichel, 2005; Ferguson \& Zimmerman, 2005; Johnson \& Howard, 2002; Johnson \& Wiechelt, 2004; Tusaie \& Dyer, 2004; Youssef \& Luthans, 2007).

3. Draw on inner strengths, skills and support (Johnson \& Wiechelt, 2004) in order to maintain psychological wellbeing and health, despite risks, threats and adversity (Ferguson \& Zimmerman, 2005; Johnson \& Howard, 2002).

Ferguson and Zimmerman (2005) explain that resilience refers to the process of overcoming the negative effects of risk exposure, coping successfully with traumatic experiences and avoiding the negative trajectories associated with risks. A key requirement of resilience is the presence of risks and promotive or protective factors that help bring about a positive outcome, reduce or avoid a negative outcome (Ferguson \& Zimmerman, 2005; Visser, 2007; Windle, 2011). Risk factors in the workplace may include clearly destructive and dysfunctional experiences like stress, burnout, poor health, unemployment and inadequate education (Luthans et al., 2007).

Consequently, resilience implies avoiding the problems associated with being vulnerable by using protective mechanisms. One can locate these mechanisms either externally (extrinsically) or internally (intrinsically) in people. Internal protective mechanisms are assets, like confidence and determination, whilst one can find external protective factors in the social or external environment of people, like family support. These are resources (Visser, 2007). Therefore, whilst a strong sense of personal agency is important for negotiating adversity, one can also regard the availability of resources from the level of family and community as important (Windle, 2011).

However, the focus of resilience goes beyond the sum of one's assets and risk factors because it incorporates the adaptation processes and mechanisms that combine assets and risk factors in a cumulative and interactive pattern (Luthans et al., 2008).

Youssef and Luthans (2007) point out that several unique characteristics distinguish resilience from other psychological capacities like hope, optimism and other positive capacities. Resilience has closer links to the need to take proactive and reactive measures in the face of adversity. A person's capacity to be resilient promotes the recognition and acknowledgement of adversities, allowing the affected person the time, energy and resource investment to recover, rebound and return to equilibrium. Proactively, resilience also allows for the use of setbacks as "springboards" or opportunities for growth beyond that equilibrium point.

Several researchers emphasise the notion that resilient people expect and maintain good and positive outcomes (Hjemdal et al., 2006; Kruger \& Prinsloo, 2008; Siebert, 2005). They also tend to regard life's challenges as opportunities for proactive learning, growth and development (Kruger \& Prinsloo, 2008; O'Rourke, 2004; Strumpfer, 2003; Theron, 2004; Youssef \& Luthans, 2007). Walsh (2003) argues that resilience does not mean bouncing back unscathed, but rather struggling well, working effectively through and learning from adversity as well as attempting to integrate the experience into the fabric of one's life. People who are resilient usually transcend stressful situations and flourish, often even beyond their previous state of equilibrium.

Windle (2011) analysed the concept of resilience from a range of disciplinary perspectives and defines resilience as the process of effectively negotiating, adapting to or managing significant sources of stress or trauma. The assets and resources of people, their lives and environments facilitate this capacity for adaptation and 'bouncing back' in the face of adversity. The experience of resilience will vary across their life courses (p. 163).

Several researchers emphasise that resilience is clearly a multidimensional construct that varies with context, time, age, gender, social support systems, family environments and cultural origins, as well as individual capabilities (Jowkar, Friborg, \& Hjemdal, 2010; Lever \& Valdez, 2010; Windle et al., 2011). The discussion that follows will make it clear that Visser's (2007) approach to the development of the ARI reflects this multilevel and multidimensional perspective of resilience.

\section{The Adult Resilience Indicator}

The ARI (Visser, 2007; 2009), is currently the only South African resilience questionnaire that measures resilience in adults. It assesses the presence or absence of vulnerability and resilience-promoting factors (internal assets and external resources) that people can draw on in times of hardship, which can also improve their potential.

Visser's (2007, 2009) research is consistent with Windle's (2011) suggestions that we need: 
- More clarity about the definition of resilience.

- A thorough methodological assessment to ensure that a robust scientific approach underpins it.

The purpose of Visser's $(2007,2009)$ research was:

- To explore the concept of adult resilience and to identify and describe the protective and vulnerability factors that play roles in adult resilience.

- to develop an adult resilience scale that researchers could use as an indicator of the presence or absence of resiliencepromoting and vulnerability factors whilst supporting the identified factors with appropriate theory.

Visser $(2007,2009)$ conducted the process of developing the questionnaire in two phases. Firstly, Visser conducted a qualitative investigation to identify the attributes of resilience. In this phase, Visser defined resilience from the perspective of 'normal' working people - in other words, how ordinary people view resilience and what they attribute to it (Visser, 2007; 2009). During this phase, the definition of resilience that Visser presented to the participants was 'the ability to jump back after facing hardship or adversity' (Visser, 2007, p. 89). Visser identified different themes. They embraced the multidimensional aspects of resilience.

In the second phase of development, Visser constructed items for the questionnaire that attempted to capture the meaning of these identified themes. Visser included statements like: 'When faced with adversity, difficulties or problems in my life, I keep a positive outlook'. Respondents indicated, on a five-point Likert scale, whether the statement is 1 (almost never true of me), 2 (rarely true of me), 3 (sometimes true of me) 4 , (often true of me) or 5 (almost always true of me).

The first version of the ARI consisted of 82 items. Visser gave them to 146 call-centre employees to complete. Visser then subjected the items to several rounds of principal component factor analysis with a varimax rotation in order to examine the underlying factor structure of the questionnaire (Visser, 2007; 2009).

After this process, Visser eliminated 30 items, because of cross loading of 0.30 or more, and retained a final factor solution of eight factors that comprised 52 items. After further exploratory factor analysis, Visser eliminated another 15 items (W.A. Visser, personal conversation, January 2012). Therefore, the final questionnaire Visser used for the purposes of this study consisted of 37 items.

\section{Visser's final eight factors}

1. Confidence and optimism: This includes self-confidence and confidence in one's own ability to overcome adversity. It also refers to having an optimistic view of the future and expecting that all will end well, whilst maintaining a positive outlook under duress.

2. Positive reinterpretation: This refers to the ability to reinterpret the current situation in a positive way, especially during difficult times, whilst trying to turn it into something positive. It also includes the ability to try to find some meaning in what has happened and to learn from bad or difficult experiences.
3. Facing adversity: This is the willingness of resilient people to face adversity and to have the courage to live up to it even when it seems to be unpleasant.

4. Support: Resilient people use social support, which can be present in the form of friends and/or family. They actively try to find support, to get help from others, to reach out to them and to ask them for support. Therefore, they have a support base that carries them through difficult times.

5. Determination: This refers to continue doing something despite opposition or obstacles. Overcoming challenges refers to overcoming obstacles, not losing heart and refusing to accept failure.

6. Negative rumination and helplessness: This factor reduces the resilience of people and is a vulnerability factor. It refers to people who do not harbour negative feelings about the difficulties that they face or become bitter. They work through their sadness, do not feel sorry for themselves (have no self-pity) and do not become negative about their problems.

7. Religion: This factor includes faith and religion. It shows resilient people as people who have faith in a higher power and have a strong belief that the higher power will help them during difficult times. They also engage in some form of religious practice, like praying.

8. Emotional regulation: This refers to the ability to regulate emotions, especially negative ones.

Therefore, it is clear that the ARI is a multilevel measure that assesses multidimensional aspects of resilience, which Jowkar et al. (2010) regard as necessary, yet scarce. Fergus and Zimmerman (2005) conclude that resilience studies usually include single risks and a single promotive factor instead of realising that several risks actually threaten most people, that most people could have several assets and could have access to several resources. Windle et al. (2011) explain that the development of a measuring instrument that can assess a range of protective mechanisms in several domains provides an approach to operationalising resilience as a dynamic process of adapting to adversity. Therefore, measures of resilience should be able to reflect the complexity of the concept. The ARI measures a range of protective mechanisms (assets and resources) and vulnerabilities. It also reflects the complexity of the resilience. Furthermore, it fits well with the notion of resilience as a dynamic process.

Compared to the three measures of adult resilience that had the best psychometric ratings in the study of Windle et al. (2011) - the Resilience Scale for Adults (Friborg et al., 2003), the Connor-Davidson Resilience Scale (Connor \& Davidson, 2003) and the Brief Resilience Scale (Smith et al., 2008) - only the ARI and the Resilience Scale for Adults examine resilience across several levels and reflect conceptual adequacy. The ARI, with its eight factors, measures a broader range of dimensions than any of these questionnaires do (see Table 1). It is only one of two instruments with a spiritual or religious dimension.

\section{Research design Research approach}

In order to conduct the research, the current study used a cross-sectional design with a technique for collecting survey 
TABLE 1: Description of resilience measures.

\begin{tabular}{|c|c|c|c|}
\hline Instrument & Developers & Dimensions measured & Level of measurement \\
\hline Connor-Davidson Resilience Scale & Connor \& Davidson (2003) & $\begin{array}{l}\text { Measures stress coping ability. Five factors: } \\
\text { Personal competence; trust, tolerance or the strengthening } \\
\text { effects of stress; acceptance of change and secure } \\
\text { relationships; control; and spiritual influences }\end{array}$ & $\begin{array}{l}\text { Resilience is seen as a personal quality that } \\
\text { reflects the ability to cope with stress. An } \\
\text { individual level measure. }\end{array}$ \\
\hline Resilience Scale for Adults (RSA) & Jowkar et al. (2010) & $\begin{array}{l}\text { Examines intrapersonal and interpersonal protective factors. } \\
\text { Five factors: } \\
\text { Personal competence; social competence; family cohesion; } \\
\text { social resources; and structural style }\end{array}$ & $\begin{array}{l}\text { Assesses multidimensional aspects of } \\
\text { resilience -including assets and resources. } \\
\text { A multilevel measure. }\end{array}$ \\
\hline Brief Resilience Scale & Smith et al. (2008) & $\begin{array}{l}\text { Designed as an outcome measure to assess the ability to } \\
\text { bounce back and recover from stress. Six items }\end{array}$ & $\begin{array}{l}\text { Items all reflect a sense of personal agency. } \\
\text { An outcome measure in the context of } \\
\text { stress. }\end{array}$ \\
\hline Adult Resilience Indicator & Visser $(2007,2009)$ & $\begin{array}{l}\text { An indicator of the presence or absence of resilience promoting } \\
\text { and vulnerability factors. Eight factors: confidence and optimism; } \\
\text { positive reinterpretation; facing adversity; support; } \\
\text { determination; negative rumination and helplessness; religion; } \\
\text { and emotional regulation }\end{array}$ & $\begin{array}{l}\text { Assesses multidimensional aspects of } \\
\text { resilience, including vulnerabilities, assets } \\
\text { and resources. A multilevel measure. }\end{array}$ \\
\hline
\end{tabular}

data. In addition, the current study used a cross-validation strategy to determine the stability of the most appropriate factor structure of the ARI.

The authors compared two competing measurement models of the ARI to determine the most appropriate factor structure to use during cross-validation.

The first measurement model presented the original factor structure, as Visser (2007, 2009) proposed. The second measurement model assumed that the ARI had a onedimensional factor structure.

Researchers should use the better fitting model when conducting cross-validation. The most appropriate way to conduct cross-validation is to split a large sample (even if it uses non-probability sampling) randomly into two groups. The first group is the calibration sample whilst the second group is the validation sample (Byrne, 2006).

The authors first evaluated the goodness of fit of the proposed structure of the ARI using the calibration sample. They then replicated the results they obtained from the calibration sample in the validation sample. They then compared the results of these two groups (the calibration and validation samples) to determine significant differences in the proposed structure of the ARI. Therefore, they used cross-validation to provide a second confirmation (using the validation sample) of the validity of the ARI's structure they obtained during initial testing (using the calibration sample) (Byrne, 2006).

\section{Research method}

\section{Research participants}

From a population of 1800 first-year students enrolled for a course in industrial psychology at a higher education institution in South Africa, 789 students participated in the study.

The authors selected the participants using non-probability sampling or convenience sampling. Most of the students were female (57\%) and between 18 and 20 years old $(80.10 \%)$. Nearly 15\% (14.96\%) were between 21 and 25 years old; $2.79 \%$ were between 26 and 30; whilst only $2.15 \%$ were older than 30 . In terms of home language, most of the students (approximately 53\%) spoke an African language: Sesotho (24.59\%), Setswana (13.05\%), IsiXhosa (6.84\%), IsiZulu (44\%), Sepedi (2.53\%) and TshiVenda (1.14\%). Furthermore, 35.74\% had Afrikaans as their home language, 6.97\% were English speaking and $4.69 \%$ spoke other languages. With regard to the degrees for which they were registered, most of the students (56.16\%) were studying B.Com, $11.41 \%$ B.Soc.Sc, $13.43 \%$ B.Accounting and $11.28 \%$ were studying for a B.A. degree. Approximately eight per cent $(7.73 \%)$ of students indicated their study field as 'Other'.

\section{Research procedure}

After the authors had presented the research project and proposal to the research committee of the faculty in which they were conducting the research, they received permission for the project and ethical clearance.

The authors presented the research project to the first-year students during class sessions. They discussed the aim of the research, as well as the data-gathering instrument the students would need to complete if they decided to participate in the project with them. The authors made it clear to the students that participation would be voluntary and assured the students that they would adhere to ethical issues like confidentiality. The authors made practical arrangements for completing the questionnaire with those participants who consented to the study.

The questionnaire consisted of a biographical section (Section A) that included information about gender, home language, age and degree for which the students had enrolled. Section B consisted of the 37-item Adult Resilience Indicator that measures eight dimensions of resilience. Respondents indicated on a five-point Likert scale whether the statement is 1 (almost never true of me), 2 (rarely true of me), 3 (sometimes true of me) 4 , (often true of me) or 5 (almost always true of me).

The authors gave verbal and written instructions before the students completed the ARI. They collected the questionnaires immediately after the students had completed them.

\section{Statistical analysis}

The authors used confirmatory factor analysis (CFA) to compare and evaluate the two competing measurement 
models of the ARI. They treated the data as continuous. Through analysing the covariance matrix, the authors assessed the data for normality (Jackson, Gillaspy \& PurcStephenson, 2009). They conducted a test of multivariate normality to determine whether the data violated the assumption of normality (Jöreskog, 2006).

The results suggested that the data deviated from normality in terms of skewness and kurtosis. Researchers may use bootstrapping, data transformation and item parcelling to remedy non-normality. Researchers may also delete outliers. However, these approaches are not recommended (Brown, 2006). Trimming or changing the data to achieve multivariate normality need not always reflect the true nature of the empirical data (Hair, Black, Babin, Anderson \& Tatham, 2006; Field, Miles \& Field, 2012). A more appropriate approach is to use the robust maximum likelihood method of estimation when analysing non-normal data for the purposes of CFA (Brown, 2006).

The authors conducted all the analyses related to the confirmatory factor analysis using LISREL 8.80 (Jöreskog, 2006). They used several fit indices, including the SatorraBentler Scaled Chi-square, root mean square error of approximation (RMSEA), standardised root-mean square residual (SRMR), the Comparative Fit Index (CFI) and the Goodness of Fit Index (GFI). Values close to 0.95 for GFI and CFI indicate good model fit. Values close to 0.06 indicate acceptable fit for RMSEA, whilst values smaller than 0.08 are acceptable for SRMR (Hu \& Bentler, 1999). In addition, researchers use Akaike's Information Criterion (AIC) for comparing competing measurement models, where smaller values indicate a better fit of the proposed model (Byrne, 2006).

The authors used Cronbach's Alpha $(\alpha)$ and the Rho coefficient to estimate the reliability associated with the dimensions of the ARI. The former uses the assumption that the measurement model is one-dimensional with both the factor loadings and error variances being equal (Byrne, 2006, p. 133). These assumptions are not always realistic, given that measurement models may be multidimensional in nature. Model-based coefficients are better. The Rho coefficient provides a model-based reliability estimate of internal consistency (Byrne, 2006). Reliability estimates that are 0.7 and higher indicate good reliability. However, estimates as low as 0.6 may be acceptable when conducting exploratory research (Hair et al., 2006, pp. 137, 778).

In order to investigate the stability of the proposed structure, the authors performed cross-validation. Researchers should follow a sequential process of comparing less constrained measurement models with more constrained measurement models when they perform cross-validation (Byrne, 2006; Hair et al., 2006). Researchers use this process to reveal evidence of invariance. Lack of invariance will be present when there are no statistically significant differences between the constrained model and the less constrained model (Byrne, 2006; Hair et al., 2006).

The authors used the corrected S-B Chi-square difference test to detect invariance in constrained and less constrained models (Byrne, 2006; Cheung \& Rensvold, 2002; Meade, Johnson, \& Braddy, 2008; Satorra \& Bentler, 2001). Researchers must use the corrected S-B Chi-square difference test when the Robust Maximum-Likelihood method of estimation yields the Satorra-Bentler Chi-square value - which does not have the same distribution as the Maximum-Likelihood Chisquare. Invariance will be present if the corrected S-B Chisquare difference test is non-significant (Cheung \& Rensvold, 2002; Meade et al., 2008).

\section{Results}

Table 2 gives information on the approximate fit indexes the authors calculated using LISREL 8.80 .

When one compares the original factor structure of the ARI with a one-dimensional factor structure, the former is a better fitting measurement model. From Table 2 it is clear that the original factor structure of the ARI has smaller values associated with Akaike's Information Criterion. The other approximate fit indices also support a good fitting model. In both samples, the CFI is above the recommended guideline of 0.95. Both the RMSEA and SRMR are below the recommended cut-off. In contrast, the goodness-of-fit statistics associated with the one-dimensional factor structure indicate an inferior model with poor levels of fit.

Table 3 gives information on the cross-validation process the authors followed to determine invariance across the calibration and validation samples.

TABLE 2: Summary of the goodness-of-fit statistics of the two random samples.

\begin{tabular}{lcccc}
\hline Variable & \multicolumn{2}{c}{ Calibration sample $(\boldsymbol{n}=\mathbf{3 9 5})$} & & Validation sample $(\boldsymbol{n}=\mathbf{3 9 4})$ \\
\cline { 2 - 3 } \cline { 5 - 5 } & Original structure & $\begin{array}{c}\text { One-dimensional } \\
\text { structure }\end{array}$ & & Original structure \\
\hline S-B $\chi^{2}$ & 853.30 & 3747.00 & & 778.50 \\
$d f$ & 601 & 629 & 601 \\
RMSEA & 0.033 & 0.112 & & 0.027 \\
SRMR & $(0.0 .27 ; 0.038)$ & $(0.109 ; 0.116)$ & & $(0.022 ; 0.033)$ \\
CFI & 0.046 & 0.099 & 0.049 \\
AIC & 0.98 & 0.79 & 0.99 \\
\hline
\end{tabular}

S-B $\chi 2$, Satorra-Bentler Scaled Chi-square; $d f$, degrees of freedom; RMSEA, root mean square error of approximation; SRMR, standardised root mean square residual; CFI, Comparative Fit Index; AIC, Akaike's Information Criterion.

TABLE 3: The cross validation.

\begin{tabular}{|c|c|c|c|c|c|c|}
\hline Type of invariance & S-B $\chi^{2}$ & $d f$ & RMSEA & CFI & NFI & Sig. $\Delta$ in S-B $\chi^{2}$ \\
\hline Unknown parameters are assumed to be different & 1640.64 & 1218 & 0.030 & 0.99 & 0.95 & - \\
\hline Equal factor loadings & 1656.18 & 1247 & 0.029 & 0.99 & 0.95 & No \\
\hline Equal factor loadings and covariances & 1679.46 & 1262 & 0.029 & 0.99 & 0.95 & No \\
\hline Equal factor loadings, covariances and error variances & 1713.28 & 1304 & 0.028 & 0.99 & 0.95 & No \\
\hline Equal factor loadings, covariances, error variances and means & 2534.72 & 1370 & 0.037 & 0.98 & 0.94 & Yes \\
\hline
\end{tabular}

S-B $\chi^{2}$, Satorra-Bentler Scaled Chi-square; $d f$, degrees of freedom; RMSEA, root mean square error of approximation; CFI, Comparative Fit Index; NFI, Normative Fit Index. 
It is clear from Table 3 that the authors obtained support for invariance (in terms of equal factor loadings, covariances and error variances) and that the proposed structure of the Adult Resilience Indicator is very stable across the two random samples. This is evident from the non-significant changes in the corrected S-B Chi-square difference test - except where they concern equality of means.

Tables 4, 5 and 6 give information about the $\varphi$ coefficients (correlations between the latent constructs in the measurement model) as well as the reliabilities associated with each of the eight sub-scales.

It is clear from Table 4 and Table 5 that the eight sub-scales have low to moderately sized $\varphi$ coefficients. It is worth noting that the 'negative rumination and helplessness' dimensions as well as the 'religion' dimension have lower intercorrelations with the other dimensions of the ARI. Furthermore, Table 6 shows that most of the dimensions of the Adult Resilience Indicator have acceptable reliabilities, with both the 'support' and 'positive reinterpretation' dimensions having the best internal consistencies. In contrast, the 'facing adversity' dimension is slightly below the recommended 0.7 cut-off.

Table 7 gives information about the standardised factor loadings for the calibration and validation samples.

It is clear from Table 7 that the standardised factor loadings of both the samples are not exactly the same. This is most evident in the loadings for both the 'confidence and optimism' and 'positive reinterpretation' dimensions. The loadings associated with the 'religion' dimension seem to be similar. However, these differences did not produce a significant change in the S-B Chi-square difference test - except with regard to unequal means.

\section{Discussion}

The main objective of the study was to assess the psychometric properties of the South African Adult Resilience Indicator (ARI), specifically with regard to its factor structure and reliability. Previous research has clearly shown that reliable and valid resilience measures are necessary. The assessment of current resilience instruments and publication of the psychometric development and evaluation of these instruments are also necessary.

This study is one of the first to report on the psychometric properties of the ARI in a young adult sample. The results show that the psychometric properties of the ARI are adequate. The most important finding is that the original factor structure of the ARI is stable when one replicates it in a validation (second) sample. More specifically, the authors have provided evidence of partial measurement invariance across calibration and validation samples.

The hypothesised factor structure was equivalent across the calibration and validation samples - except with regard to equality of means. However, the latter is no cause for concern given that the authors still obtained partial measurement equivalence (Byrne, 2006). These findings speak well for the cross-validation of this structure. Given the findings of the cross-validation, the overall goodness of fit of the eight dimensions is acceptable (RMSEA $=0.027$; CFI $=0.99$; SRMR 0.049 ) - as is clear from the calibration sample. The reliabilities are also acceptable (they range between 0.69 and 0.89 ).

Although the psychometric properties of the ARI seem acceptable in terms of both reliability and goodness of fit, it is important to compare these results with other measures

TABLE 4: The Phi matrix (validation sample).

\begin{tabular}{|c|c|c|c|c|c|c|c|c|}
\hline Items & $\mathrm{COO}$ & PRI & FA & SUP & DET & NRH & REL & ER \\
\hline 1 & 1.00 & - & - & - & - & - & - & - \\
\hline 2 & 0.59 & 1.00 & - & - & - & - & - & - \\
\hline 3 & 0.66 & 0.69 & 1.00 & - & - & - & - & - \\
\hline 4 & 0.34 & 0.47 & 0.36 & 1.00 & - & - & - & - \\
\hline 5 & 0.68 & 0.58 & 0.72 & 0.25 & 1.00 & - & - & - \\
\hline 6 & 0.32 & 0.30 & 0.23 & 0.11 & 0.26 & 1.00 & - & - \\
\hline 8 & 0.39 & 0.61 & 0.62 & 0.30 & 0.50 & 0.18 & 0.29 & 1.00 \\
\hline
\end{tabular}

COO, confidence and optimism; PRI, positive reinterpretation; FA, facing adversity; SUP, support; DET, determination; NRH, negative rumination and helplessness; REL, religion; ER, emotional regulation.

TABLE 5: The Phi matrix (calibration sample).

\begin{tabular}{|c|c|c|c|c|c|c|c|c|}
\hline Items & $\mathrm{COO}$ & PRI & FA & SUP & DET & NRH & REL & ER \\
\hline 1 & 1.00 & - & - & - & - & - & - & - \\
\hline 2 & 0.66 & 1.00 & - & - & - & - & - & - \\
\hline 3 & 0.62 & 0.56 & 1.00 & - & - & - & - & - \\
\hline 4 & 0.37 & 0.45 & 0.32 & 1.00 & - & - & - & - \\
\hline 5 & 0.76 & 0.70 & 0.63 & 0.41 & 1.00 & - & - & - \\
\hline 6 & 0.47 & 0.32 & 0.18 & 0.25 & 0.39 & 1.00 & - & - \\
\hline 7 & 0.24 & 0.25 & 0.31 & 0.25 & 0.26 & 0.07 & 1.00 & - \\
\hline 8 & 0.40 & 0.58 & 0.43 & 0.36 & 0.51 & 0.31 & 0.13 & 1.00 \\
\hline
\end{tabular}

COO, confidence and optimism; PRI, positive reinterpretation; FA, facing adversity; SUP, support; DET, determination; NRH, negative rumination and helplessness; REL, religion; ER, emotional regulation. 
of adult resilience. This will enable the current study to determine whether the psychometric properties of the ARI are as good as, or better than, the existing measures of adult resilience. The researchers used both the Resilience Scale for Adults (RSA) (Friborg et al., 2003) and the Multiracial Challenges and Resilience Scale (MCRS) (Salahuddin et al., 2011) for comparison purposes. In a review of resilience scales (Windle et al., 2011), the RSA received some of the best psychometric ratings.

TABLE 6: Reliability estimates $(n=789)$.

\begin{tabular}{llll}
\hline Dimension & Number of items & Cronbach's Alpha & Rho factor \\
\hline COO & 5 & 0.789 & 0.790 \\
PRI & 7 & 0.853 & 0.856 \\
FA & 3 & 0.687 & 0.688 \\
SUP & 6 & 0.893 & 0.895 \\
DET & 4 & 0.707 & 0.708 \\
NRH & 6 & 0.818 & 0.820 \\
REL & 4 & 0.735 & 0.743 \\
ER & 2 & 0.702 & 0.777 \\
\hline
\end{tabular}

$\mathrm{COO}$, confidence and optimism; PRI, positive reinterpretation; FA, facing adversity; SUP, support; DET, determination; NRH, negative rumination and helplessness; REL, religion; ER, emotional regulation.
When comparing the psychometric properties of the ARI with the RSA, the results of the current study are on a par with, and better than, two previous studies (Jowkar et al., 2010; Hjemdal et al., 2011) reported. Compared to the first study, the ARI showed better levels of fit with regard to the RMSEA, SRMR and CFI. In addition, the reliabilities associated with the dimensions of the ARI were higher. Compared to the second study, the ARI showed similar levels of fit with regard to the RMSEA and CFI. However, the ARI provided better fit in terms of SRMR. In addition, the reliabilities associated with the dimensions of the ARI were similar to those that the second study reported.

The psychometric properties of the ARI seem to be better than those of the MCRS. The ARI showed better levels of fit with regard to the RMSEA, SRMR and CFI. In addition, the reliabilities associated with the dimensions of the ARI were similar to those that Hjemdal et al. (2011) reported.

The authors found no support for the one dimensionality of the ARI. In addition, the variation of the low to moderately sized $\varphi$ coefficients in the subscales of the ARI indicates

TABLE 7: Standardised factor loadings in both samples.

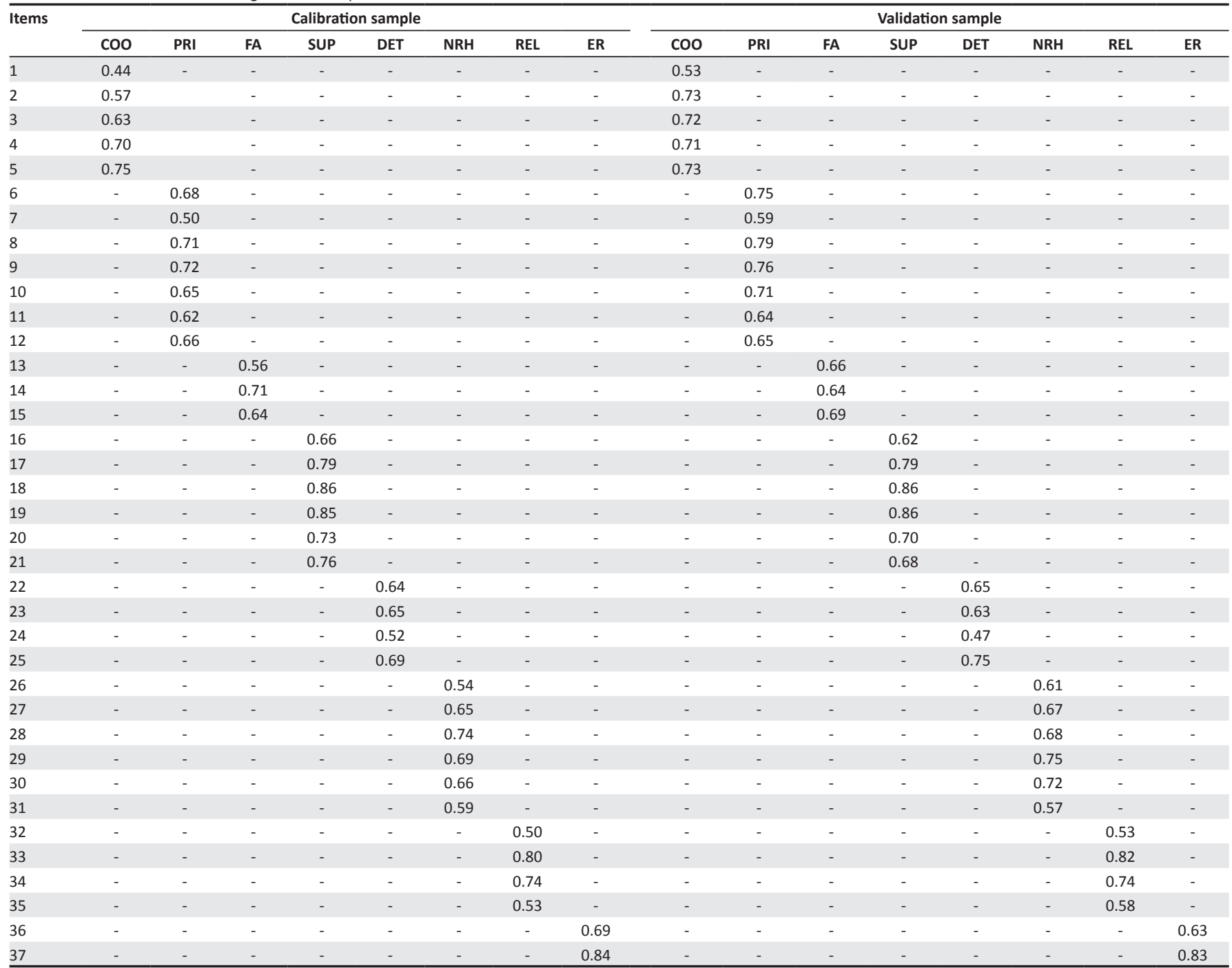

$\mathrm{COO}$, confidence and optimism; PRI, positive reinterpretation; FA, facing adversity; SUP, support; DET, determination; NRH, negative rumination and helplessness; REL, religion; ER, emotional regulation. 
that these subscales measure different, but various positive aspects, of the resilience concept. These findings support the theoretical argument that one should treat resilience as a multidimensional construct (Mandleco \& Peery, 2000).

These findings are encouraging given that the 'emotional regulation' dimension consists of two items only, whilst the other dimensions included between four and six items. Therefore, it seems that one can identify these dimensions.

In summary, when one compares the psychometric properties of the ARI with other measures of adult resilience, the results are promising. This indicates that the instrument can stand its ground against other resilience scales.

\section{Practical implications}

Previous research has clearly shown that reliable and valid resilience measures are necessary, that it is necessary to assess the psychometric properties of the currently available instruments and that it is necessary to publish the results.

The current study has helped to fill this gap by examining the psychometric properties of the South African Adult Resilience Indicator (Visser, 2007; 2009). This study has confirmed the reliability and factor structure of the instrument. This allows researchers and practitioners to use the instrument to measure resilience in young adults in South Africa. The results can help researchers and practitioners, who are interested in measuring resilience in young adults, to choose a resilience measure and to make a more appropriate selection for their populations and contexts.

When they use the ARI as a research tool, investigators can be confident about using this instrument as a valid and reliable measure of a multidimensional resilience construct. As a developmental tool, the ARI could also be quite useful.

Because researchers regard resilience as a positive statelike psychological construct that is open to development (Youssef \& Luthans, 2007), the developmental nature of resilience allows researchers to establish and implement micro-interventions that focus on enhancing these positive strengths. People who want to increase their resilience should first establish the areas on which they need to concentrate. They can achieve this by completing a reliable and valid instrument in order to identify assets, resources and vulnerabilities as they relate to the process of building resilience. The ARI can be very valuable for determining the strengths and weaknesses in the resilience of people, especially in the South African context.

Based on these results, researchers can develop resilience interventions that focus on enhancing external and internal protective factors, taking responsibility and transforming stress into resilience.

Masten and Reed (2002) identified three sets of resilience development strategies and adapted them specifically to the workplace (Luthans et al., 2007). These include asset-focused, risk-focused and process-focused strategies. Several other researchers and practitioners have also developed resilience interventions that have been effective in various contexts, like the workplace, education, leadership development and change-management situations (Connor \& Davidson, 2003; Reivich \& Shatté, 2002; Waite \& Richardson, 2004; Wolin \& Wolin, 1993). Therefore, the ARI can assist managers and practitioners to focus their interventions on the specific resilience needs of the employees in their organisations.

\section{Limitations}

A possible limitation of the present study is the sample of participants and that all were university students. One should be careful about generalising the results to the general adult population in South Africa. Further validity studies on other samples, in terms of occupation, could address this uncertainty.

Furthermore, to provide additional evidence of the construct validity of the ARI, further studies could use another resilience questionnaire, like the Resilience Scale for Adults (RSA), together with the ARI, to compare the results of the ARI with the results of the other resilience questionnaire.

\section{Conclusion}

The authors conclude that the psychometric properties of the ARI are adequate. The overall goodness of fit of the eight dimensions that the instrument measures and their reliabilities are acceptable. When they use the ARI as a research and/ or development tool, researchers and practitioners can be confident about using this instrument as a valid and reliable measure of a multilevel and multidimensional resilience construct.

Although the 'emotional regulation' dimension of the ARI provided acceptable psychometric properties, in terms of reliability and significant factor loadings, the fact that it consists of only two items may require further investigation. The authors suggest that future studies explore the possibility of adding additional items (like behavioural indicators) to improve the content validity of this dimension. They also suggest that future studies investigate the appropriateness of using the ARI with different populations (like different age and cultural groups and in different contexts), but also specifically in the workplace.

\section{Acknowledgements}

The authors thank Dr Willie Visser for providing the Adult Resilience Indicator, and the information about its development, for this research.

\section{Competing interests}

The authors declare that they have no financial or personal relationship(s) that may have inappropriately influenced them when they wrote this article.

\section{Authors' contributions}

M.K. (University of the Free State) and P.N. (University of the Free State) contributed equally to the writing of this article. 


\section{References}

Ahern, N.R., Kielh, E.M., Sole, M.L., \& Byers, J. (2006). A review of instruments measuring resilience. Issues in Comprehensive Paediatric Nursing, 29, 103-125. $\mathrm{http}: / / \mathrm{dx}$.doi.org/10.1080/01460860600677643

Arehart-Treichel, J. (2005). Resilience shown in youth protects against adult stress. Psychiatric News, 40(1), 14. PsychiatryOnline. Retrieved from http:// pn.psychiatryonline.org/cgi/content/full/40/17/14

Avolio, B.J., \& Luthans, F. (2006). The high impact leader: Authentic, resilient leadership that gets results and sustains growth. New York, NY: McGraw-Hill.

Bartone, P.T. (1989). Predictors of stress related illness in city bus drivers. Journal of Occupational Medicine, 31, 657-663. http://dx.doi.org/10.1097/00043764 198908000-00008

Block, J., \& Kremen, A.M. (1996). IQ and ego-resiliency: Conceptual and empirical connections and separateness. Journal of Personality and Social Psychology, 70 349-361. http://dx.doi.org/10.1037/0022-3514.70.2.349

Brown, T.A. (2006). Confirmatory factor analysis for applied research. New York, NY: Guilford Press. http://dx.doi.org/10.1080/00036810600603377

Byrne, B.M. (2006). Structural equation modelling with EQS: Basic concepts, applications and programming (2nd edn.). Mahwah, NJ: Erlbaum. http://dx.doi. org/10.1207/s15328007sem1302_7

Carvalho, M.V.A., Calvo, F. B., Martin, H.L., Campos, R.F., \& Castillo, C.I. (2006) Resilience and the burnout-engagement model in formal caregivers of the elderly. Psicothema, 18(4), 791-796. Retrieved from http://www.ncbi.nlm.nih.gov/ pubmed/17296119

Cheung, G.W., \& Rensvold, R.B. (2002). Evaluating goodness-of-fit indexes for testing measurement invariance. Structural Equation Modeling, 9, 233-255. http:// measurement invariance. Structural Equation
dx.doi.org/10.1207/S15328007SEM0902 5

Connor, K.M., \& Davidson, J.R. (2003). Development of a new resilience scale: The Connor-Davidson Resilience Scale (CD-RISC). Depression and Anxiety, 18(2), 7682. http://dx.doi.org/10.1002/da.10113, PMid:12964174

Field, A., Miles, J., \& Field, Z. (2012). Discovering statistics using R. Thousand Oaks, CA: Sage Publications.

Ferguson, S., \& Zimmerman, M.A. (2005). Adolescent resilience: A framework for understanding healthy development in the face of risk. Annual Review of Public Health, 26, 399-419. http://dx.doi.org/10.1146/annurev. publhealth.26.021304.144357, PMid:15760295

French, S.L., \& Holden, T.Q. (2012). Positive organizational behavior: A buffer for bad news. Business Communication Quarterly, 75, 708-220. http://dx.doi. org/10.1177/1080569912441823

Friborg, O., Hjemdal, O., \& Stiles, T.C. (2010). Resilience and personality. Bulletin of Psychology, 63, 457-462.

Friborg, O., Hjemdal, O., Resonvinge, J.H., \& Martinussen, M. (2003). A new rating scale for adults' resilience: What are the central protective resources behind healthy adjustment? International Journal of Methods in Psychiatric Research 12(2), 65-76. http://dx.doi.org/10.1002/mpr.143, PMid:12830300

Griffith, D. (2007). A New Year's resolution for your emotional health. Retrieved from www.healthatoz.com

Hair, J.F., Black, W.C., Babin, B.J. Anderson, R.E., \& Tatham, R.L. (2006). Multivariate data analysis (6th edn.). Upper Saddle River, NJ: Prentice Hall.

Hjemdal, O., Friborg, O., Braun, S., Kempenaers, C., Linkowski, P., \& Fossion, P. (2011). The Resilience Scale for Adults: Construct validity and measurement in a Belgian sample. International Journal of Testing, 11, 53-70. http://dx.doi.org/10.1080/1 5305058.2010.508570

Hjemdal, O., Friborg, O., Stiles, T.C., Martinussen, M., \& Rosenvinge, J.H. (2006). A new scale for adolescent resilience: Grasping the central protective resources
behind healthy development. Measurement of Evaluation in Counseling and behind healthy developm
Development, 39, 84-96.

Hu, L., \& Bentler, P.M. (1999). Cut-off criteria for fit indexes in covariance structure analysis: Conventional criteria versus new alternatives. Structural Equation analysis: Conventional criteria versus new alternatives. Structural
Modeling, 6, 1-55. http://dx.doi.org/10.1080/10705519909540118

IEA European Questionnaire Group. (2005). Epidemiology deserves better questionnaires. Retrieved March, 04, 2013, form http//www.iea-europe.org/ download/Questionnaires.pd

Jackson, D.L., Gillaspy, J.R., \& Purc-Stephenson, R. (2009). Reporting practices in confirmatory factor analysis: An overview and some recommendations. Psychological Methods, 14(1), 6-23. http://dx.doi.org/10.1037/a0014694

Johnson, J., Gooding, P., Wood, A.M., \& Tarrier, N. (2010). Resilience as positive coping appraisals: Testing the schematic appraisals model of suicide (SAMS). Behaviour Research and Therapy, 48, 179-186. http://dx.doi.org/10.1016/j. Behaviour Research and Therap
brat.2009.10.007, PMid:19906364

Johnson, L., \& Wiechelt, S.A. (2004). Introduction to the special issue on resilience. Substance Use and Misuse, 3, 657-670. http://dx.doi.org/10.1081/JA-120034010

Johnson, M.O., \& Howard, S. (2002). Quantifying and evaluating resilience-promoting factors: Teacher's beliefs and perceived roles. Research in Education, 70, 50-64.

Jöreskog, K.G. (2006). Formal inference-based recursive modeling [LISREL]. Hillsdale, NJ: Lawrence Erlbaum Associates.

Jowkar, B., Friborg, O., \& Hjemdal, O. (2010). Cross-cultural validation of the Resilience Scale for Adults (RSA) in Iran. Scandinavian Journal of Psychology, 51, 418-425.

Kotzé, M., \& Lamb, S. (2012). The influence of personality traits and resilience on burnout among customer service representative in a call centre. Journal of Social Sciences, 31, 295-309.
Kruger, L., \& Prinsloo, H. (2008). The appraisal and enhancement of resilience modalities in middle adolescents within the school context. South African Journa of Education, 28, 241-259.

Lever, P., \& Valdez, J. (2010). Construction of a measurement scale of resilience in Mexicans (RESI-M). Interdisciplinaria, 27(1), 7-22.

Luthans, F. (2002). Positive organizational behaviour: Developing and managing psychological strengths. Academy of Management Executive, 16, 57-72. http:// dx.doi.org/10.5465/AME.2002.6640181

Luthans, F., Avey, J.B., Clapp-Smith, R., \& Li, W. (2008). More evidence on the value of Chinese workers' psychological capital: A potentially unlimited competitive resource? International Journal of Human Resource Management, 19, 818-827. http://dx.doi.org/10.1080/09585190801991194

Luthans, F., Avolio, B., Avey, J., \& Norman, S. (2007). Psychological capital: Measurement and relationship with performance and satisfaction. Personality Psychology, 60, 541-572. http://dx.doi.org/10.1111/j.1744-6570.2007.00083.x

Luthans, F. L., Youssef, C., \& Avolio, B.J., (2007). Psychological capital: Developing the human capital edge. Oxford, UK: Oxford University Press.

Mandleco, B.L., \& Peery, J.C. (2000). An organizational framework for conceptualizing resilience in children. Journal of Child and Adolescent Psychiatric Nursing, 13, 99-111. http://dx.doi.org/10.1111/j.1744-6171.2000.tb00086.x

Masten, A.S. (2001). Ordinary magic: Resilience processes in development. American Psychologist, 56, 227-238. http://dx.doi.org/10.1037/0003-066X.56.3.227, PMid:11315249

Masten, A.S., \& Reed, M.G.J. (2002). Resilience in development. In C.R. Snyder, \& S Lopez (Eds.). Handbook of positive psychology, (pp. 74-88). Oxford, UK: Oxford University Press.

Meade, A.W., Johnson, E.C., \& Braddy, P.W. (2008). Power and sensitivity of alternative fit indices in tests of measurement invariance. Journal of Applied Psychology, 93, 568-592. http://dx.doi.org/10.1037/0021-9010.93.3.568, PMid:18457487

Miller, G.A. (2003). The cognitive revolution: A historical perspective. Trends in Cognitive Sciences, 7(3), 141-144. http://dx.doi.org/10.1016/S13646613(03)00029-9

Moenkemeyer, G., Hoegl, M., \& Weiss, M. (2012). Innovator resilience potential: A process perspective of individual resilience as influenced by innovation project termination. Human Relations, 65, 627-655. http://dx.doi. org/10.1177/0018726711431350

Norman, S.M., Avey, J.B., Nimnicht, J. L., \& Pigeon, N.G. (2010). The interactive effects of psychological capital and organizational identity on employee organizational citizenship behaviors. Journal of Leadership and Organizational Studies, 17, 380391. http://dx.doi.org/10.1177/1548051809353764

O'Rourke, N. (2004). Psychological resilience and the well-being of widowed women Ageing International, 29, 267-280. http://dx.doi.org/10.1007/s12126-996-1002-x

Ollier-Malaterre, A. (2010). Contributions of work-life and resilience initiatives to the individual/organisation relationship. Human Relations, 63(1), 41-62. http:// dx.doi.org/10.1177/0018726709342458

Ong, A.D., \& Bergeman, C.S. (2004). Resilience and adaptation to stress in later life: Empirical perspectives and conceptual implications. Ageing International, 29 219-246. http://dx.doi.org/10.1007/s12126-996-1000-z

Reivich, K., \& Shatté, A. (2002). The resilience factor. New York, NY: Broadway Books.

Salahuddin, N.M., \& O'Brien, K.M. (2011). Challenges and resilience in the lives of urban, multiracial adults: An instrument development study. Journal of Counseling Psychology, 58, 494-507. http://dx.doi.org/10.1037/a0024633, PMid:21823788

Satorra, A., \& Bentler, P.M. (2001). A scaled difference chi-square test statistic for moment structure analysis. Psychometrika, 66, 507-514. http://dx.doi. org/10.1007/BF02296192

Siebert, A. (2005). The resiliency advantage. San Francisco, CA: Berrett-Koehler Publishers.

Sinclair, V.G., \& Wallston, K.A. (2004). The development and psychometric evaluation of the Brief Resilient Coping Scale. Assessment, 11(1), 94-101. http://dx.doi. org/10.1177/1073191103258144, PMid:14994958

Smith, B.W., Dalen, J., Wiggins, K., Tooley, E., Christopher, P., \& Bernard, J. (2008). The Brief Resilience Scale: Assessing the ability to bounce back. International Journal of Behavioural Medicine, 15, 194-200. http://dx.doi. org/10.1080/10705500802222972

Strumpfer, D.J.W. (2003). Resilience and burnout: A stitch that could save nine. South African Journal of Psychology, 33, 69-79. http://dx.doi. org/10.1177/008124630303300201

Theron, L.C. (2004). The role of personal protective factors in anchoring psychological resilience in adolescents with learning disabilities. South African Journal of Education, 24, 317-321.

Tusaie, K., \& Dyer, J. (2004). Resilience: A historical review of the construct. Holistic Nursing Practice, 18(1), 3-8.

Ungar, M., Liebenberg, L., Boothroyd, R., Kwong, W.M., Lee, T.Y., Leblanc, J., Duque, L. \& Makhnach, A. (2008). The study of youth resilience across cultures: Lessons from a pilot study of measurement development. Research in Human Development, 5 166-180. http://dx.doi.org/10.1080/15427600802274019

Villabos-Galvis, F.H., Arevalo-Ojeda, C., \& Rojas-Rivera, F.D. (2012). Resilience inventory adjustment to the suicide (SRI-25) in adolescents and young people in Colombia. Rev Panam Salud Publica, 31(3), 233-239.

Visser, W.A. (2007). Daily hassles, resilience and burnout of call centre staff, Unpublished PhD thesis, North-West University, Potchefstroom, South Africa. 
Visser, W.A. (2009, September 21-22). The development of the Adult Resilience Indicator. Paper presented at the wellness in the workplace conference, llanga Estate, Bloemfontein, South Africa.

Wagnild, G.M., \& Young, H.M. (1993). Development and psychometric evaluation of the Resilience Scale. Journal of Nursing Measurement, 1, 165-178.

Waite, P., \& Richardson, G.E. (2004). Determining the efficacy of resiliency training in the worksite. Journal of Allied Health, 33(3), 178-183.

Walsh, F. (2003). Family resilience: A framework for clinical practice. Family Process, 42(1), 1-18. http://dx.doi.org/10.1111/j.1545-5300.2003.00001.x

Windle, G. (2011). What is resilience? A review and concept analysis. Reviews in Clinical Gerontology, 21, 152-169. http://dx.doi.org/10.1017/ S0959259810000420
Windle, G., Bennett, K.M., \& Noyes, J. (2011). A methodological review of resilience measurement scales. Health and Quality of Life Outcomes, 9(8), $11-18$.

Wolin, S.J., \& Wolin, S. (1993). The resilient self: How survivors of troubled families rise above adversity. New York, NY: Villiard Books.

Youssef, C. (2004). Unique leadership: The case of Mother Teresa. In J. Burns, G. Goethals, \& G. Sorenson (Eds.), Encyclopedia of leadership (pp. 1032-1036). Great Barrington, MA: Berkshire/Sage.

Youssef, C.M., \& Luthans, F. (2007). Positive organizational behaviour in the workplace: The impact of hope, optimism and resilience. Journal of Management, 33, 774800. http://dx.doi.org/10.1177/0149206307305562 